\title{
Some Other Country's History
}

\author{
Carole Scott
}

$\mathrm{I}$ take my title from a Jules Pfeiffer cartoon I saw many years ago on the noticeboard outside the door of a professor of history. While some of the details have become vague in my mind, my memory of the last two panels remains very sharp. The page-long series of panels featured a middle-aged man in a construction hard-hat. 'When I was in school,' he says, 'they taught us how' and here I'll have to improvise a little 'we Americans pioneered this great continent; we opened up the land; we created a new nation dedicated to freedom, liberty and justice for all.' The sequence continues: 'Now my kid's in school. They're teaching him how we killed off the original inhabitants; how we stole their land; how we oppressed them.' And now l can stop improvising to fill in the gaps because I remember the last two panels so clearly. 'No wonder there's no patriotism any more,' he says. 'They're teaching my kid some other country's history.'

A nation's history is an intangible and evanescent construct, kaleidoscopic in that a slight rearrangement of the pattern produces a very different story, and political in that those who control the history decide which events are significant and how they are interpreted. Historians Appleby, Hunt and Jacob tell us that 'even in a democracy, history always involves power and exclusion, for any history is always someone's history, told by that someone from a partial point of view' (1994, p.11) or as James Harvey Robinson said, 'what passes for history in any generation is what Voltaire called une fable convenue only one of the many, many stories which could be told of man's doings.' (Novick 1988, p.250). The telling of the story, as John Stephens points out, involves narratological imperatives, for even sincere attempts at "telling it how it was" tend implicitly to mask more complex issues such as the retrospective construction of causality and the impossibility of creating narrrative without a point of view.' (1992, p.202).

Linda Hutcheon's The Politics of Postmodernism also considers the notion of ordering events in which writers of history and fiction engage. Her chapter 'Re-presenting the past' delves particularly into the relationship of history and postmodernism, and she notes that it is "the process of making stories out of chronicles, of constructing plots out of sequences [that] postmodern fiction underlines. This does not in any way deny the existence of the past real, but it focuses attention on the act of imposing order on that past, of encoding strategies on meaning-making through representation.' (1989, pp.66-7)

Unfortunately, while historians recognize the intangibility of their subject, and literary critics understand the impossibility of "trying to "forge truth" from "facts" (Stephens 1992, p.202) the general public's desire for patriotic linchpins presses for those "shared sentiments, symbols and social explanations [that are] necessary for an integrative national identity' (Appleby 1994, p.11). In a recent article in The New Republic, Pauline Maier writes of 'the public and its pundits [who] invariably rework th[e] past into a convenient shorthand that mixes half truths with reassuring fictions,' and concoct what she terms a 'civic religion' (1997, pp.34-38)

Many children's history books do perpetuate these stereotypic symbols of the nation's past. But a good number of works of children's literature have used the device of time travel or time slip to immerse their protagonists, and their young readers, in a more personal and more immediate experience of historical events or milieux, offering them a fictive role in their national historical legacy. 1 am thinking, for example, of Puck of Pook's Hill, and more recently The Root Cellar and Playing Beatie Bow.

Less common in the past, but increasingly evident as ethnic writers find a place among the published, are the children's books that reinterpret past events from an alternative viewpoint, one that may have been ignored. suppressed or denied, presented by spokespersons formerly excluded from the clique of the nation's official storytellers. These new perspectives often bring ar. exploration of the history-making process and a probing of the essential value of history and the significance of the past in shaping our present environment and thus ou! lives and character. I have selected two very differen books as examples of non-traditional perspectives it reinterpreting history. The first is Frank Chin's Donals Duk, a postmodern, metafictive novel which examine American history from the point of view of a fourth generation Chinese American whose forebears immigrate 
to the United States. The second is Daisy Utemorrah's Do Not Go Around the Edges, a picturebook which combines poems and autobiographical verbal narrative written by Utemorrah, with illustrations by Pat Torres. Both Utemorrah and Torres are Australian Aboriginal artists, and Utemorrah's history is that of an indigenous person in a post-colonial setting, her country taken over by people from other lands, and her culture submerged.

Frank Chin's Donald Duk charts the recovery of the Chinese-American role in American history as it lays bare the cynicism of the history makers and the perversion of the historical process. Donald Duk is almost twelve, the traditional threshold of manhood in Chinese culture, and is experiencing not only the usual growing pains of his agegroup, but the bi-cultural tensions of a fourth generation Chinese American. His name serves as an ongoing point of conflict, for though he is named after the famous Chinese opera singer, it makes him a laughing stock for Americans who visualize "that barebutt cartoon duck in the top half of a sailor suit and no shoes' (Chin 1991, p.7)

Donald's feelings of exclusion from mainstream American culture are initially expressed in his attempts to reject his Chinese background. In school, his teacher Mr. Meanwright instructs the class that 'the Chinese in America were made passive and nonassertive by centuries of Confucian thought and Zen mysticism. They were totally unprepared for the violently individualistic and democratic Americans. From their first step on American soil to the middle of the twentieth century, the timid, introverted Chinese have been helpless against the relentless victimization by aggressive, highly competitive Americans', or, as Donald interprets the message, 'Chinese are artsy, cutesy and chickendick.' (pp.2-3). In one of his imagined conversations with his idol Fred Astaire he complains that Chinese-Americans should be less, passive, more competitive, 'more American', 'American! like you and me. The kind of people who make American history. The kind of people actors play in American movies. '(p.92).

As the work progresses, Donald becomes increasingly aware of the distortion that the dominant culture has imposed upon the perception of the Chinese American, the falsification of events in which Chinese Americans have been involved, and the exclusion of their significant contributions to the building of and history of Ameri The basic elements of the struggle between reality and perception are introduced at the very beginning of book in a photograph of Chinese laying the track wh Donald's uncle shows him in an 'old railroad bor belonging to his father. This photograph serves as realistic frame for Donald's dream sequences where finds himself amongst his forebears, working to constr the historic transcontinental railroad that linked nation's Eastern and Western communities and oper up the continent. The tension between what is dre: myth, or imaginative reconstruction and the actual eve we like to call true history, is a central focus of Chi work and a direct attack on the manipulation of nation's story by those who hold power, in this case white Americans. 'What's fair?' asks Donald's fatl 'History is war, not sport! ... You gotta keep the hist. yourself or lose it forever, boy.' (p.123)

Like the presentation of many traditional time-slip wo of children's literature, the dream sequences are of realistically presented, detailed and full of event. Char: with excitement and emotion-laden, they provide Don: and the reader, with an immediate sense of experie and understanding of the period and the people invols But Chin creates a surreal overlay by bringing Chin mythical and wisdom figures into the scenes, addin special intensity to the experiences and providing a ! to ancient Chinese culture heroes whose historical ic are clouded and confused with imaginative storytelli The ultimate effect of mixing these genres is to spotli the process of human experience and memory. perception and reality, and the ambiguous concep 'fact', which cannot exist independent of a hypothesi an ideological model.

This technique is reiterated in even more complex fo in Chin's presentation of the scenes from Donald's $c$ to-day life. His sisters in particular continu: communicate through role playing, expressing themsel in verbal fragments from popular media and lites allusion, so that dialogue is constructed from layer association, imbedded quotation, and other peop voices. His father, a famous chef, constructs the arti of his cuisine in a bicultural milieu infused with mu 
opera, poetry and philosophy, where culinary magic transforms the ordinary into the exotic, reflected not only in the tastes, but in the language that describes them: "I don't say sliced cross-section of broccoli spear alternate with slices of Virginia ham and chicken breast. Sounds too laboratory science. Who wants to eat some kind of autopsy? Ugh! So, I say Jade Tree Golden Smoke Ham and Chicken.' (p.124) Chinese cultural myth, legend, philosophy and opera are continually referenced and brought into the action of the book and expressed in the lives of the people. Finally the interspersion of various dialects, accents, and words from different languages constantly remind us of the complex nature of human experience, the kaleidoscopic nature of perception and the absurdity of attempting to reduce history to a single narrative, which, as Stephens has pointed out, implies a retrospective causality and point of view (1992, pp.206-7).

Donald's dreams involve conversations which express the thinking that lies behind the exclusion of the 'heathens' from the story of the transcontinental railroad. Of special interest is the confrontation between Donald and historical figures Union Pacific Vice President T. C. Durant and Charles Crocker of Central Pacific. Asked why the Chinese workers have written their names on the final crosstie, Donald explains,

'We don't want anyone to forget who laid these crossties and spiked this track.'

'. . and built this railroad?' T.C Durant coaxes with a sly eyebrow toward the writers and artists present.

'. . and built this railroad, 'Donald Duk says.

'You are just a little boy. You are too young to understand how history is made, ' responds Crocker.

(p. 128)

Charles Crocker promises Durant that

'there will not be a heathen in sight at tomorrow's ceremonies [when the last spike is driven]. I will ... keep them away, with force of arms if need be. ... The Last Spike will be hammered home, the telegram sent, our photograph made to preserve a great moment in our nation's history, without the Chinese. Admire and respect them as I do. I will show them who buill the railroad. White men. White dreams. White brains and white brawn.'

(p.131)

To ensure that the Chinese effort goes unrecognized, the final crosstie triumphantly inscribed with the names of all the Chinese workers who had labored passionately to lay the railroad was tom from the track and obliterated from history.

The immediacy of his dream experiences, where spectacular feats of work by hard-driving Chinese whose ambitious teamwork breaks the world record for laying track, impel Donald to action. He embarks, with his caucasian friend Arnold Azalea, on library research to try to understand the nature of the events as they were reported and to test his dream-information against it. Their research uncovers the falsification of the historical record, for the official pictures of the May tenth ceremony of completion include no Chinese at all, just as Donald's dream had revealed, and the only names listed are those of eight Irishmen who worked with the 1200 Chinese to lay the track. But other books, with photographs taken prior to that date, include the thousands of Chinese whose labour had built the railroad, record the statistical details of the construction ( 125 tons of iron, 25,000 ties, 3,520 nails, 28,160 spikes, 14,800 bolts used in a single day) and even record the tearing out of the final, autographed crosstie.

With the knowledge he has gained, Donald confronts Mr. Meanwright in the classroom, telling him that the book he uses as his guide in class has misrepresented the character of the Chinese people and their part in building America, and that 'it is badly informed people like you who keep us out of that picture' (p.150). Supported by the library' materials that Arnold has brought, Donald's viewpoint prevails, and Mr. Meanwright backs down in the face of alternative information and a new interpretation. The teamwork of Donald and Arnold, Chinese and European Americans, suggests an optimistic outcome to cultural diversity and understanding.

Unlike the long, rich, written cultural history of the Chinese, the history of the Aboriginal peoples is more 
fragile because it depends so heavily on oral transmission. In addition, because of its strong mythical and philosophical identification with the land itself, the Aboriginal history has been made even more vulnerable by the claiming of the land by the white invaders and the uprooting of its people.

Do Not Go Around the Edges by Daisy Utemorrah, an Australian Aboriginal writer, expresses rather than analyses how it feels to be excluded from one's nation's history. The work contraposes a series of poems framed within a bordered illustration, against the 'Story About My Life', written in prose outside the illustration and thus literally around the edges of the featured work. The combination of forms of communication is intriguing, for in its weaving together of different strands of fact and affect, experience and memory, nostalgia and philosophy, pictures and words, the voice of one person and the images of another, it emphasises the way that history itself is shaped. Although, on the face of it, the language of this work is quite simple when compared to the verbal complexity of Chin's book, closer analysis reveals subtle and complicated relationships in the presentation which communicate many layers of meaning, voices and points of view. For these reasons it is offered as an example of writing described as postmodern and metafictive in Stephens and Watson's From Picture Book to Literary Theory $(1994$, p.46)

The italicized text of 'The Story About my Life', printed in the red ochre colour which matches the heavy, quarterinch border that frames the main illustration, is a primarily factual text with some personal commentary, and includes the major events of Utemorrah's life. The two, three or four lines of text occupy the space between the bottom frame of the illustration and a second line, a quarter inch from the bottom of the page, the corners of which turn upward for $13 / 4$ inches to enclose a small triangular line drawing of three figures in a design repeated on each page; these miniature figures are taken from the illustration of the Wandjinas. The overall effect is one of a framed picture set on a decorated mat reproduced on a page. It is reminiscent of a photograph pasted into a photograph album with written commentary under each picture.

To complicate the presentation, the top of the illustration appears to run over the top of the page, for the white framing which surrounds the heavy red frame on bottom and left and right sides, is not reproduced al top. Instead the image reaches to the edge of the $p$ : and gives the sense that a piece has been cut Additionally, the poems which appear almost alway. the right hand spread are encapsulated within illustration, and themselves framed by two narrow ochre lines.

This series of frames within frames accentuates sense of fragments of history, of snapshots of $t$ captured in word and image, and support the feelin fragmentation of experience that the book presents. fragmentation of an individual's life and of a peop culture. Furthermore, the positioning of the elem on the page with the prose events set in the wide bot frame and the illustration cut off at the top, gives impression that the present story of acculturatio literally pushing the Aboriginal culture off the $p$. And, while the presence of the miniature figures o1 Wandjinas at the bottom corners carry throughout book a reminder of the past, for these three figures $\xi$ the land and the rules that accompany the land to Aboriginal peoples, the reader questions whether $t$ incorporation into the border is a statement of valu whether they have been reduced to a decorative funct

At the beginning of the book, facing the Table of Cont is a photograph of Daisy Utemorrah, framed with a gi border, the bottom right hand corner of which is ope a partially framed map of the area in Western Aust? that is Utemorrah's homeland. Within the map, in bottom right-hand corner, is a very small image of Australian continent and indicates the position of Western Australian section given in detail.

This photograph and map show how the person territory appear from a European-Australian perspeci These contrast with all of the other illustrations in book which represent the indigenous Australian sen: land, people, animals, plants and mythical beings, $u$ symbolic shapes, decorative motifs, and other asf. characteristic of Aboriginal art. The illustrations! been created by an Aboriginal artist and exemplify a Western style and a very different sense of reality an 
being in the world. The disparity between the two once again urges the notion of two points of view, two modes of perception that provide alternate interpretations of events.

The poems are printed in a font which matches that of the prose text, but the words are not italicized, and they are printed in black ink, not red. The contrast in the presentation is matched by the contrast in the kind of communication that is taking place. The commentary is predominantly factual, with analytical or emotional comments brief and somewhat flat in affect. For example, 'When I was five I went to school; I had to face it', we were '... helping the women to water. That wasn't easy'; 'I enjoyed everything'; 'It was a sad thing to do'; 'One person I missed was my mother' (pp.3, 5, 7, 10, 14)

The poems, on the other hand, are often extremely emotional. For example, Utemorrah's sense of loss and of alienation from land and culture is poignantly expressed in a number of poems. 'Bind with the White Man's Law' features the call of the Mother Land:

Oh Mother Land you are crying out,

'Come back, why have you left me alone?

The white man's law still binds you.

The time will come when you must pass -

I am lost without you, thinking of the times,

the days when you were here.

so proud in your Mother Land,

full of birds singing, a nature place.

You heard frogs croaking near the pool.

Yes, goodbye Mother Land-

I am bind with the white man's law.

Another, entitled Our Mother Land, speaks even more specifically to the lost history of the dreamtime and nature echoes the despair:

Our dream and our past is buried under the ground.

When the sun rises and begins another day

all is empty, ground and hill shake on us, overwhelmed with people everywhere.

The dream the past - where does it stand now?

The burun burun whirrs in the night time
And the owl calling!

And the dingo howling!

The moon shines on the water, all is ended and the dreamtime gone.

(p.29)

The poems offer a variety of subjects. Some are observational descriptions of plants or animals, such as 'Wattle Tree' or 'A Cricket'. Other poems involve creation stories, recording Aboriginal history and philosophy, such as 'Burun Burun The Kingfisher' which tells how a dog became the evening star. Many express nature's relationship with humankind, such as 'Rain': 'I am the one who made man/ with my bare hands and with my sweav/ I will own the land!' (p.9) or 'Poet' where birds and trees laugh and twist their branches 'as if they were saying, "Come come/ I am your relative standing here." (p.21) Another communicates the human-animal connection by describing movements in language which is ambiguous, so that though the poem is called 'Cat', the movement seems to belong to a person.

I am the native cat, I dance everywhere.

I hop skip and jump, I jump on the flat stone and dance and wobble my bum and hold my hips and then dance again.

(p.23)

The illustrations which encapsulate each poem provide a variety of interrelationships with the verbal text ranging from representational to symbolic. The poem 'Galanji (Utemorrah's far away island home) is set in an illustration of blue, green and brown depicting land vegetation, sky and sea, with the decorative designs of dots, circles whorls and patterns characteristic of Aboriginal art 'Wattle Tree' captures stylized flowers, leaves and floating blossoms (similar to the American mimosa) giving bot! an impression of the tree in movement, as well as a mor: representational suggestion. Other illustrations are mor. symbolic, for example the illustration to 'Do Not G' Around the Edges' and 'Wandjinas' depict stylize figures, in the first case in a fiery context, in the seconc as stiff godlike figures (see Plates 1 and 2).

This last example is one of the many doublespread where there are very tight relationships between th 

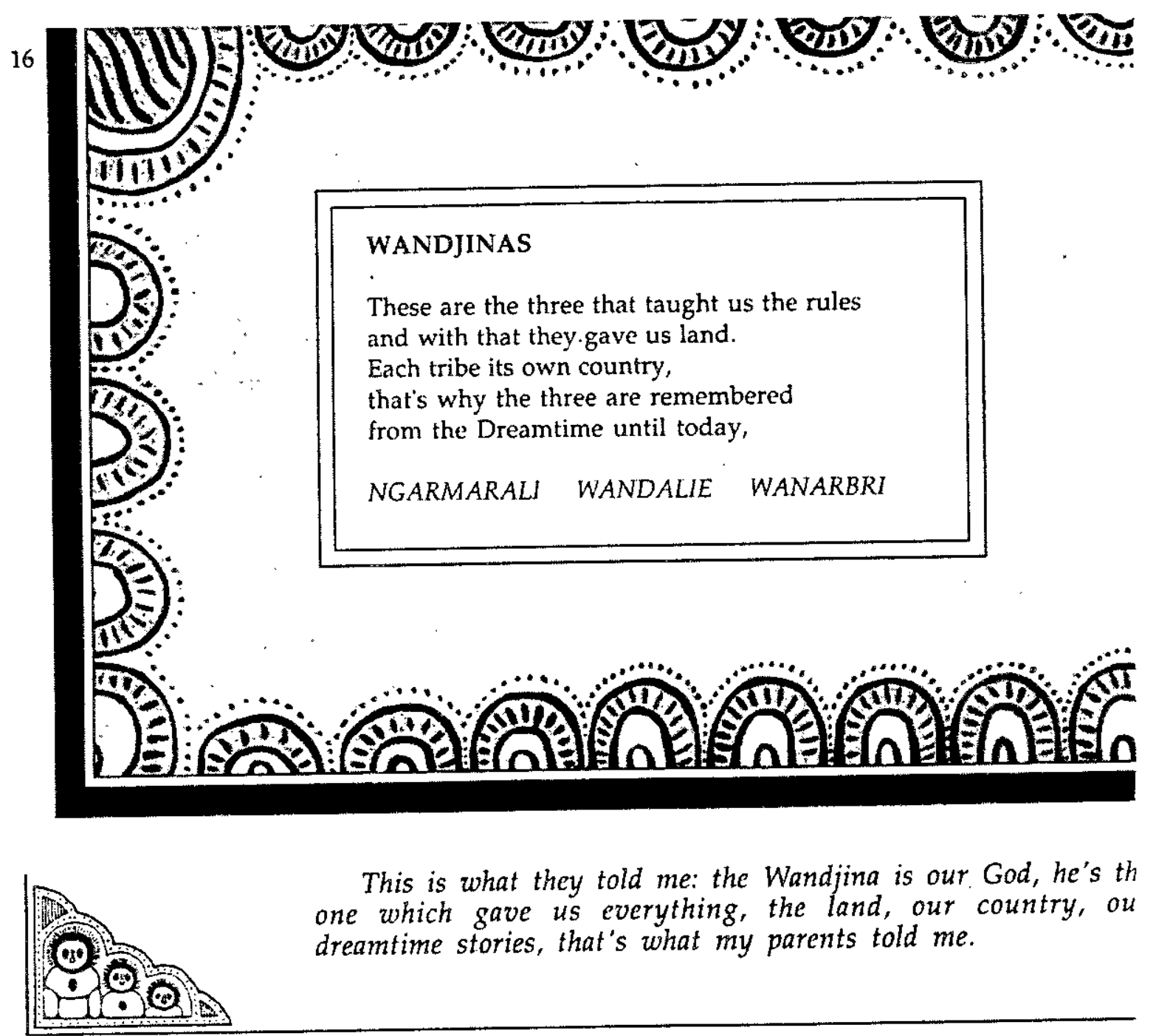

This is what they told me: the Wandjina is our. God, he's th one which gave us everything, the land, our country, ou dreamtime stories, that's what my parents told me.

Plate 1 


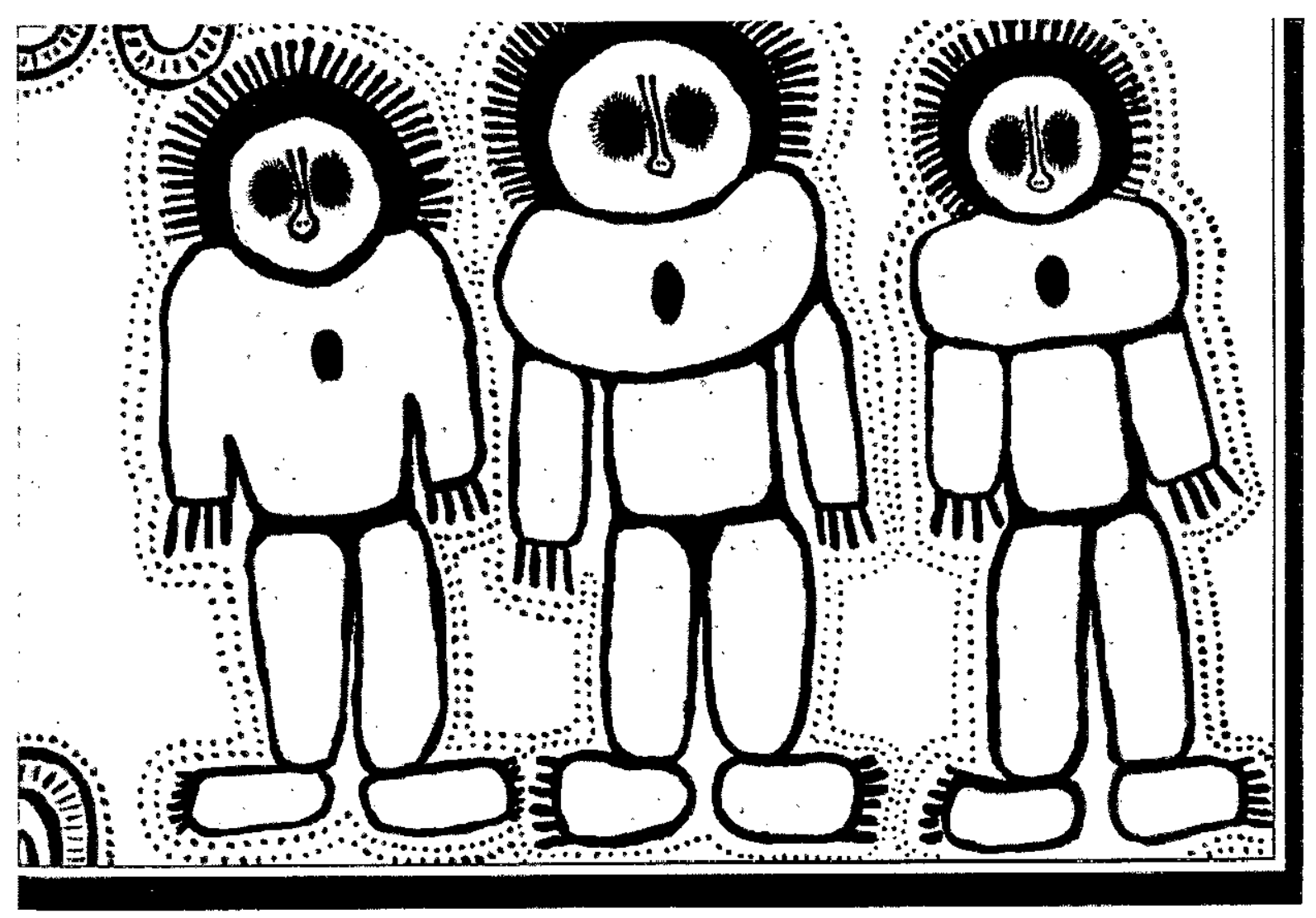

I believed the way they told me dreamtime stories; but the one in church, Mr Love, taught me about God, saying "He is the Wandjina!" My mind was swirling around. Which God should I believe, the one in the caves or the one in the sky?

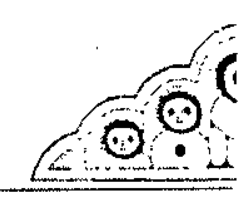

Plate 2 
poem, the prose narrative, and the illustration, for the poem explains the position of the Wandjinas as historical figures:

These are the three that taught us the rules and with that they gave us land.

Each tribe its own country,

that's why the three are remembered

from the Dreamtime until today.

\section{NGARMARALI WANDALIE WANARBRI (p.16)}

The illustration depicts the three figures (which, as noted previously, also appear in the page border) together with decorative motifs, including a dotted double line outlining each figure. Together the poem and illustration reveal the Aboriginal world, while the prose narrative beneath presents both the indigenous Australian and the EuropeanAustralian perspectives (one on the left page, one on the right) and their point of contact within Utemorrah's mind:

This is what they told me: the Wandjina is our God, he's the one which gave us everything, the land, our country, our dreamime stories, that's what my parents told me.

Ibelieved the way they told me dreamtime stories; but the one in church, Mr Love, taught me about God, saying 'He is the Wandjina!' My mind was swirling around. Which God should I believe, the one in the caves or the one in the sky?

(p.17)

This multi-media presentation of European and Aboriginal philosophies and senses of the world, and the impact on the individual caught between them, captures in just a few words and one illustration a striking picture of the culture clash between two peoples, and their disparate perceptions of 'history'. For Utemorrah, the Dreamtime and today are temporal-historical realities and the giving of the rules, the land, and the dreamtime stories are actual events. The attempts of the church to reinterpret indigenous religions to a Christian context, an effort that was undertaken in many countries, is also a documented historical fact, as is the implicit history of Christian missionaries representing a dominant world power that sought to clothe, convert and 'civilize' native peop throughout the world through the introduction of way: life and mores, religious and moral belief systems, $c$ forms of government that were forced on indigen populations.

The conflict that Utemorrah expresses here erupts many places in this book. The poem 'Bind With White Man's Law' already cited, is associated u another description of people's lives being dominated the European mores:

After a long time my father became a Christian and $\mathrm{Mr}$ Love told him to have only one wife. It was a sad thing to do in tribal ways. Yes, the separation time came and he did give away his two wives.

He wanted to keep the Wunamballady, so he gave my mother away to another old man. I called him uncle. I thought it was a joke, giving away his wives. I still stayed with my father, at the mission.

(p.11)

Utemorrah's statement 'I thought it was a joke' is cle: an example of the flat affect described earlier. As reader traces the disintegration of Utemorrah's fam the deaths and the losses, the pain, muted in her prose $t$ but surging into some of the poems, strike deep into reader's heart. For, as the poems express the loss of people's past and its conceptual expression in 'dreamtime' Daisy Utemorrah's own personal his' traces the loss of her cultural roots. Born in Kunmu Mission in February 1922, Utemorrah starts mis: school at the age of five, and when she reaches se years old she is taken from her parents and put in hostel. Both of her brothers die. Her father's conver to Christianity just described means he must renol Daisy's mother, for he already has one wife. Utemorr mother moves away and she sees her only once a s Meanwhile she is learning 'the white man's ways' also discovers that the man she thought was her fa was in fact her uncle. As described, Utemorrah is tai to substitute the white man's God for her dream' stories, takes on domestic work and is 'shifted' fron home in Kunmunya to Derby. This pattern of cutting child from the bonds of family, culture and belie: 
order for assimilation to take place is a familiar one, as are the low expectations for the children, especially females, who receive enough education to fit them only for domestic service. The distancing of emotion that the prose text illustrates is a feature of the sense of alienation, of anomie, that characterizes people caught between two cultures and that can lead to despair.

However, as in the case of Donald, Utemorrah's story takes a positive turn, for she becomes a teacher and an Assistant Cub Mistress to the Girls' Scouts. Even more important, she reclaims her past by writing her poems, recalling her childhood longings to capture the "beautiful things' in nature and 'the dreamtime stories': she also helps white linguists in recovering the Aboriginal languages she learned as a child, "help[ing] with the language to make it live again. Three languages I can talk.' (p.28). Nonetheless, although she has found for herself a place and a role in society far more meaningful than her early history portended, her sense of longing and of loss remain and are expressed in final words of the final poem. 'The moon shines on the water, all is ended -/and the dreamtime gone'. (p.29)

Both Chin's and Utemorrah's works focus explicitly and/ or implicitly on the process of history-making, and meaning-making for the individual, and involve questions not only of interpretation, but of understanding what 'really' happened. Hutcheon offers some insights that are helpful here.

The question is never whether the events of the past actually took place. That past did existindependently of our capacity to know it. Historiographic metafiction accepts this philosophically realist view of the past and then proceeds to confront it with an anti-realist one that suggests that, however true that independence may be, nevertheless the past exists for usnow-only as traces on and in the present. The absent past can only be inferred from circumstantial evidence.

(p.73)

In the case of Chin's work the past is ascertained by Donald in two ways: by research into archives and written records, and photographs, but also through imaginative dream sequences and through artistic representation. In Utemorrah's work the author herself recalls her personal experience, her own history, but which she identifies as her 'story', and also her people's cultural past residing in the 'dreamtime', an oral history that is also referred to as 'stories' but considered as events. Thus, although Donald Duk is a fictional character. while Daisy Utemorrah is not, the mingling of fact and fiction and the attempts to disentangle one from the other are equally complex, as are the attempts to understand the particular slant, perspective or ideology from which meaning is created. Hutcheon points out that

because postmodern novels focus on the process of event becoming fact, they draw attention to the dubiousness of the positivist, empiricist hierarchy implied in the binary opposing of the real to the fictive, and they do so by suggesting that the nonfictional is as constructed and as narratively known as is fiction.

(p.76)

Chin and Utemorrah, who share their sense of otherness with their readers in such potent and engaging works with their unique perspectives and specific experiences. provide an additional dimension to the understanding of the artistic nature of history-making and its political implications.

\section{REFERENCES}

Appleby, Joyce, with Hunt, Lynn, and Jacob, Margaret (1994) Telling the Truth about History. W.W. Norton. New York.

Chin, Frank (1991) Donald Duk. Minneapolis, Coffec House Press.

Hutcheon, Helen (1989) The Politics of Postmodernism. London and New York, Routledge.

Maier, Pauline (1997) 'American scripture: making the Declaration of Independence', The New Republic June 30.

Novick, Peter(1988) That Noble Dream: the 'Objectivit Question' and the American Historical Profession Cambridge, Cambridge U. Press. 
Stephens, John and Watson, Ken (eds) (1994) From Picture Book to Literary Theory. Sydney, St Clair Press.

Stephens, John (1992) Language and Ideology in Children's Fiction. London and New York, Longman.

Utemorrah, Daisy (1992) Do Not Go Around the Edges. (Illustrated by Pat Torres) Broome, Western Australia, Magabala Books Aboriginal Corporation.

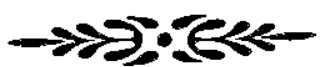

\section{ACKNOWLEDGEMENT}

The illustrations are from Do Not Go Round the Edges, illustrated by Pat Torres in collaboration with Daisy Utemorrah. Published by Magabala Books Aboriginal Corporation, Broome Western Australia, 1992, pp. 16 and 17.

Reproduced with permission.

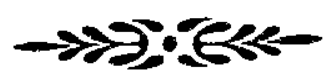

\section{BIOGRAPHICAL NOTE}

Carole Scott is Dean of the Division of Undergraduate Studies, and a member of the English and Comparative Literature Department at San Diego State University, California. She has published articles in Children's Literature, Children's Literature Association Quarterly, The Lion and the Unicorn, Orana and Papers: Explorations into Children's Literature and in collections of essays published in South Africa, Sweden, the United Kingdom and the United States. She is currently coauthoring a work on picture books with Maria Nikolajeva to be published by Garland Press.

\footnotetext{
Copyright of Full Text rests with the original copyright owner and, except as permitted under the Copyright Act 1968, copying this copyright material is prohibited without the permission of the owner or its exclusive licensee or agent or by way of a licence from Copyright Agency Limited. For information about such licences contact Copyright Agency Limited on (02) 93947600 (ph) or (02) 93947601
}

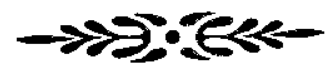

